\title{
ВЛИЯНИЕ ПЕРЕМЕННОГО МАГНИТНОГО ПОЛЯ (1-14 МТЛ) НА РОСТ И РАЗВИТИЕ КУКУРУЗЫ САХАРНОЙ
}

\section{THE INFLUENCE OF AN ALTERNATING MAGNETIC FIELD OF 1 TO 14 MILLITESLA ON THE GROWTH AND ONTOGENESIS OF ZEA MAYS L. (SUGAR CORN)}

\section{Kornienko \\ P. Kotyuk \\ A. Yaitsky}

Summary. Article gives the results of effects of an alternating magnetic field on the Zea mays $L$. seeds as a method of pre-sowing treatment of agricultural crops. It was found that irradiating Zea mays $L$. with by in an alternating magnetic field (B) of $3 \mathrm{mT}$ (millitesla) for 1 hour, yields maximum stimulating effect on plant development (of $25 \%$ compared to the control group). Amplitudes of 2, 5, 6, 7, 11, 12, 13 and $14 \mathrm{mT}$ gave an inhibitory effects. Biggest inhibitory effect (with a value of about $35 \%$ decline from the normal organism development) was given by amplitudes of 2, 11 and $13 \mathrm{mT}$. By means of evaluating of plants morphometric parameters it was established that, compared of the control group, which was not affected by an alternating magnetic field, the following amplitudes yields stimulating effects on length $(\mathrm{L})$ and diameter (D) on the corn ears: $9 \mathrm{mT}(L=19 \% ; D=18 \%), 1 \mathrm{mT}(\mathrm{L}=$ $15 \% ; D=3 \%), 4 \mathrm{mT}(\mathrm{L}=9 \% ; \mathrm{D}=15 \%), 3 \mathrm{mT}(\mathrm{L}=8 \%), 8 \mathrm{mT}(\mathrm{D}=9 \%)$. A neutral effect was detected at $B$ equal to 5 and $6 \mathrm{mT}$. Inhibitory effects were shown by amplitudes of 2, 7 and $10 \mathrm{mT}$. Evaluation of root systems at different amplitudes of alternating magnetic field showed that underground part of the plant is less susceptible to the exposure effects. 4 millitesla field had stimulating effect. With this value of magnetic induction the length of the root system was $25 \%$ better developed than in the control group, and the diameter was $8 \%$ bigger. At B $=9 \mathrm{mT}$ field strength the length of the root was $10 \%$ longer compared to the control.

Keywords: Zea mays L.; pre-sowing treatment; alternating magnetic field; magnetic induction; germination energy; ontogenesis; morphometry.
Корниенко Владимир Олегович Старший преподаватель, ГОУ ВПО «Донецкий национальный университет» kornienkovo@mail.ru

Котюк Полина Федоровна

ГОУ ВПО «Донецкий национальный университет» daniaua411@gmail.com

Яицкий Андрей Степанович

Старший преподаватель, ФГБОУ ВО «Самарский государственный социально-педагогический университет» yaitsky@sgspu.ru

Аннотация. В статье представлены результаты изучения влияния переменного магнитного поля как метода предпосевной обработки сельскохозяйственных культур на семена кукурузы сахарной (Zea mays L.). Установлено, что при облучении семян кукурузы сахарной «Пролетарская» (элита) с экспозицией в переменном магнитном поле в течение 1 часа, максимальный стимулирующий эффект в развитии растений наблюдался при магнитной индукции (В) 3 мТл (25\% от контроля). Ингибирующим эффектом отличались амплитуды 2, 5, 6, 7, 11, 12, 13 и 14 мТл. Наибольшее ингибирующее влияние, со значением $35 \%$ отклонения от нормального развития организма, оказали амплитуды 2, 11 и 13 мТл. Оценивая морфометрические параметры растений, установили, что по сравнению с контрольной группой, которая не подвергалась влиянию переменного магнитного поля, стимулирующим эффектом на длину (L) и диаметр (D) надземной части кукурузы сахарной обладали амплитуды 9 мTл ( $(\mathrm{L}=19 \%$; $D=18 \%), 1$ мТл $(L=15 \% ; D=3 \%), 4$ мТл $(L=9 \% ; D=15 \%), 3$ мТл ( $L=$ $8 \%), 8$ мТл ( $D=9 \%)$. Нейтральный эффект обнаружен при B = 5 и 6 мТл. Ингибирующее действие проявили амплитуды 2, 7 и 10 мТл. Оценивая корневую систему кукурузы сахарной, при различной амплитуде облучения переменным магнитным полем, установили, что подземная часть организма менее подвержена действию физического поля. Стимулирующим действием обладала амплитуда 4 мТл. При данном значении магнитной индукции длина корневой системы была на $25 \%$ более развитой, чем в контроле, а диаметр на $8 \%$. При В = 9 мТл длина была больше на $10 \%$ относительно контроля.

Ключевые слова: кукуруза сахарная; предпосевная обработка; переменное магнитное поле; магнитная индукция; энергия прорастания; онтогенез; морфометрия. 


\section{Введение}

B настоящее время вопросами предпосевной обработки сельскохозяйственных культур занимаются ученые-биологи (ботаники, физиологи, биофизики), физики, химики, инженеры, специалисты в области сельского хозяйства и технических наук, что говорит об особой актуальности данной проблемы [1-7]. По мнению ряда специалистов [8-10], перспективным направлением является предпосевная обработка семян переменным магнитным полем (ПеМП). Такая обработка имеет ряд преимуществ перед другими электротехнологическими методами, например это экономическая стоимость обработки, экологическая безопасность технологии и относительно простой способ применения методов предпосевной обработки. Внедрение в производство подобного экологически чистого метода обработки обусловливает необходимость установления механизма воздействия переменного магнитного поля на семена и определения наиболее эффективного режима обработки сельскохозяйственных культур [11].

Помимо проблем, связанных с подбором параметров магнитных полей на конкретную сельскохозяйственную культуру, например, кукурузу, важна и вариабельность реагирования организма на действие фактора [3]. Влияние физических факторов, в частности переменного магнитного поля, при обработке семян зерновых культур отражается на физико-химических процессах, происходящих в них. Под действием поля возрастает скорость химических и биохимических реакций в клетках (повышается растворимость находящихся в них солей и кислот [4]), происходит изменение проницаемости клеточных мембран, в результате чего ускоряется диффузия через мембрану молекул и ионов [5; 6] и увеличивается водопоглощение семян [7].

Высокая чувствительность семян некоторых сельскохозяйственных растений [12] к действию низкочастотного магнитного поля связана с изменением $\mathrm{pH}$ и высвобождением белков, которые ускоряют выход семян из состояния покоя. Такое воздействие влияет на восстановительные процессы в семени, связанные с восстановлением барьерной функции мембран [13]. Исследования С.И. Аксенова с соавторами [12] свидетельствуют об активации метаболизма при воздействии физического фактора на ряде этапов набухания семени.

В связи с вышеперечисленными проблемами при изучении влияния переменного магнитного поля на растительные организмы, в задачи настоящего исследования входило: оценить влияние ПеМП с диапазоном магнитной индукции (В) от 1 до 14 мТл, на онтогенез кукурузы сахарной; оценить влияние ПеМП, с диапазоном магнитной индукции (В) от 1 до 10 мТл, на силу роста и морфометрические параметры надземной части и корневой системы кукурузы сахарной.

\section{Материалы и метомы}

1. Установка для предпосевной обработки семян сельскохозяйственных растений. В отделе физики магнитных явлений и высокотемпературной сверхпроводимости научно-исследовательской части Донецкого национального университета (под руководством Ю.А. Лёгенького) была спроектирована магнитная установка для обработки биологических объектов. Блок-схема установки для обработки семян растений переменным магнитным полем промышленной частоты (50 Гц) представлена на рисунке 1. Установка состоит из катушки (1), в центре которой создается переменное магнитное поле, автотрансформатора (2), с помощью которого производится регулировка величины переменного тока, и вольтметра переменного напряжения (3). В центр катушки помещается стеклянный контейнер с сухими семенами. Расположение семян показано на рисунке 1 (позиция 5), и это связано с особенностями распределения магнитного поля.

2. Облучение семян. Предпосевная обработка семян кукурузы сахарной происходила в течение 1 часа при значениях магнитной индукции ПеМП в диапазоне от 1 до 14 мТл, с шагом 1 мТл. Выборка состояла из 50 семян в 3-кратной повторности. Семена обрабатывали на установке (рис. 1) в сухом состоянии, затем семена помещались в чашки Петри, при этом подложкой для семян служила влажная фильтровальная бумага. Полив осуществляли только дистиллированной водой. Семена проращивали при температуре $+20{ }^{\circ} \mathrm{C}$. Энергию прорастания и всхожесть семян определяли в сроки, указанные в ГОСТ 12038-84 [14]: на 3-е сутки (энергия прорастания) и 8-е сутки (всхожесть). Все полученные результаты обрабатывались методами вариационной статистики с использованием пакета компьютерных программ «Statistica».

3. Оценка силы роста группы семян. После обработки переменным магнитным полем семян кукурузы сахарной и дальнейшего проращивания, оценивали проростки, согласно критериям стандартного теста на всхожесть (нормально проросшие, анормально проросшие, непроросшие). Затем измеряли длину нормально проросших проростков в каждой повторности, определяли среднюю длину пяти самых длинных пророст- 
Таблица 1. Зависимость силы роста выборки семян от процентного соотношения нормально развитых проростков (по [15])

\begin{tabular}{|l|l|}
\hline Сила роста выборки & Доля нормально развитых проростков,\% \\
\hline Высокая & $80-100$ \\
\hline Средняя & $48-79$ \\
\hline Низкая & $<48$ \\
\hline
\end{tabular}

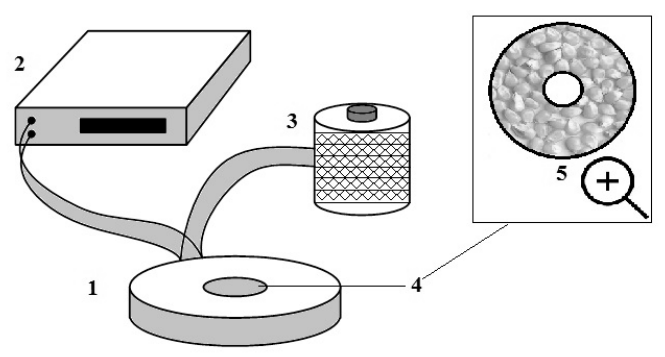

Рис. 1. Блок схема установки для обработки семян растений переменным магнитным полем промышленной частоты. Обозначения: 1 - катушка; 2 - вольтметр; 3 - автотрансформатор; 4 место для расположения контейнера для семян; 5 - схема расположения семян в контейнере

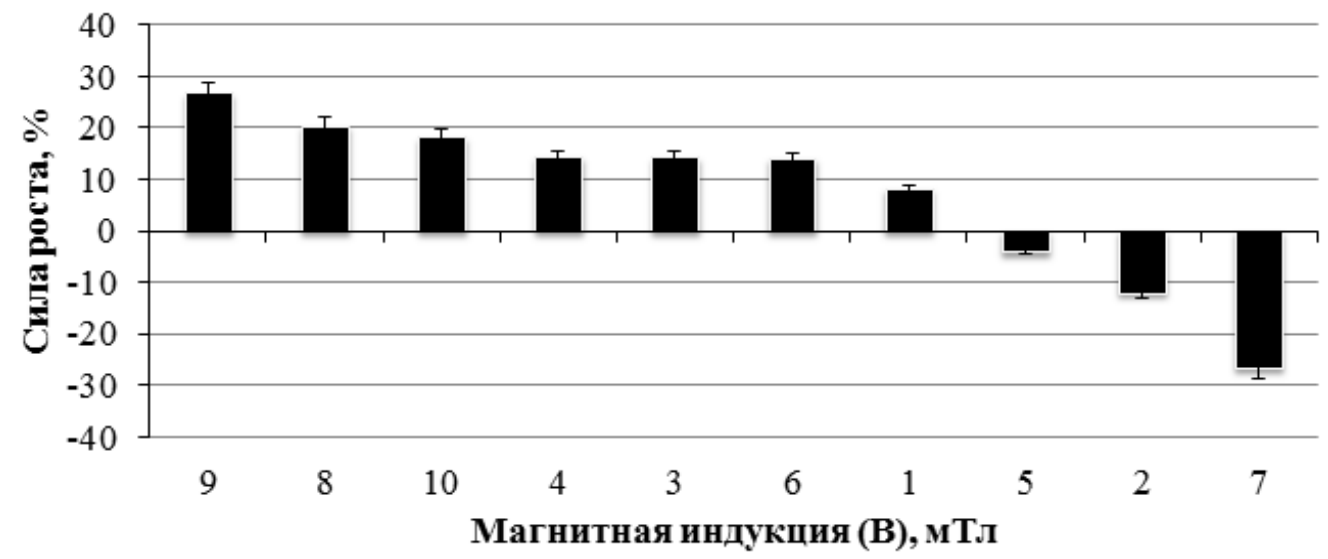

Рис. 2. Сила роста (\%) надземной части кукурузы семян сахарной в сравнении с контрольными образцами

ков (L) и умножали ее на коэффициент 0,25 [15]. Нормально проросшие проростки подразделяли на 2 категории:

а) высокая сила: нормально проросшие проростки, длиной более 0,25 × L;

б) средняя сила: нормально проросшие проростки, длиной менее $0,25 \times \mathrm{L}$.

Например, для выборки, облученной 6 мТл, длина пяти самых длинных проростков составляет 6,5, 6,7, 6,9, 6,2, 7,2 см. Затем вычислили среднюю длину этих пяти проростков $(L)=6,7$ см. Среднюю длину умножили на коэффициент 0,25. L $\approx 1,7$ см. Следовательно, все проростки длиной более 1,7 см имеют высокую силу; все проростки длиной менее 1,7 см имеют среднюю силу. Выборка семян может быть оценена по шкале (табл. 1), представленной в работе Г.Н. Алексейчук, Н.А. Ламана [15].

Проростки, которые развиваются быстро в описанных условиях, имеют высокую силу. Проростки со средней силой могут выживать при интенсивном действии фактора, но их рост и развитие будут заторможены по сравнению с первой группой. 


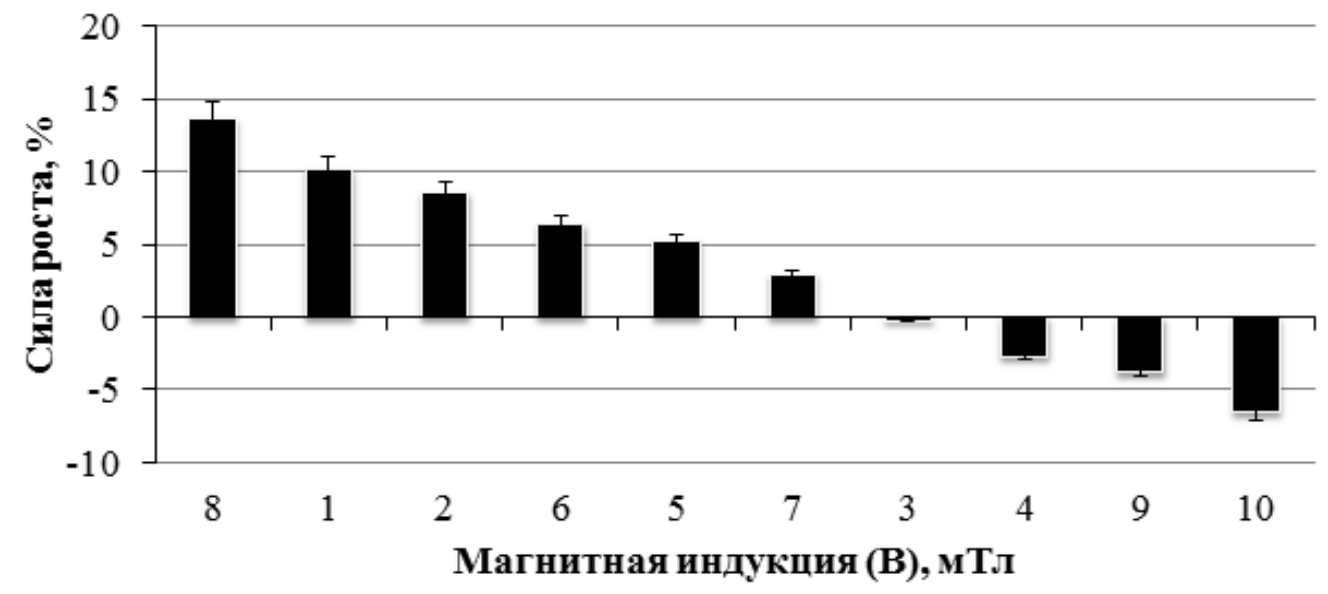

Рис. 3. Сила роста (\%) корневой системы кукурузы семян сахарной в сравнении с контрольными образцами

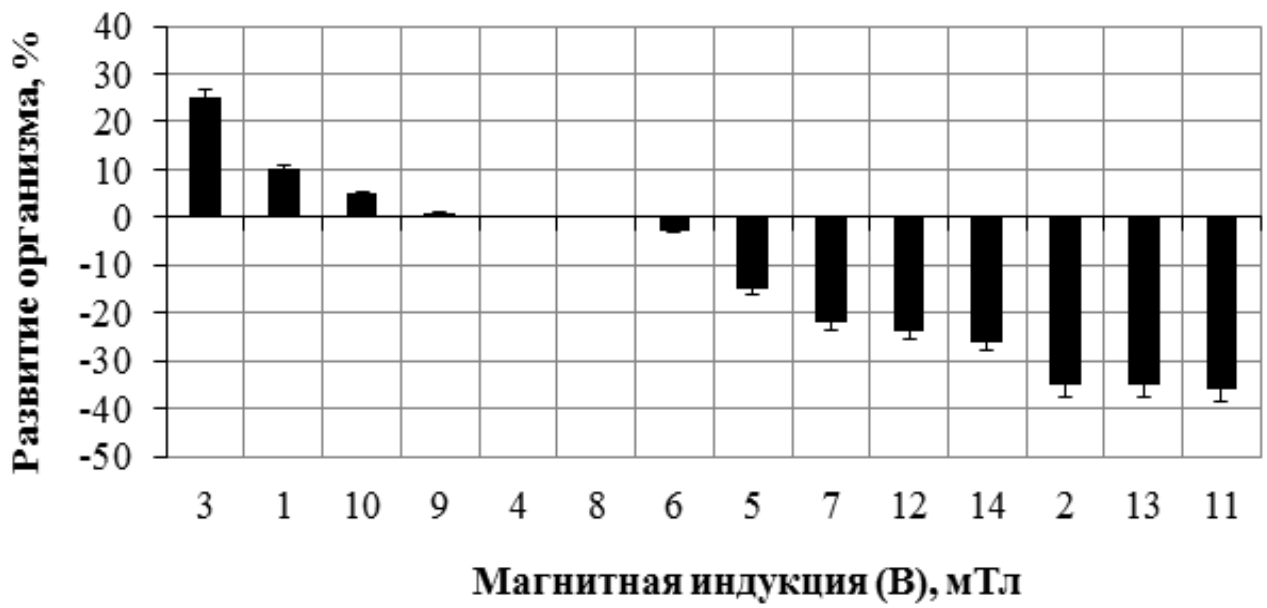

Рис. 4. Онтогенетические изменения кукурузы сахарной под влиянием переменного магнитного поля различной амплитуды на 7-е сутки

Оценку нормального развития проростков семян кукурузы сахарной, при учете энергии прорастания и всхожести, проводили по ГОСТ 12038-84 [14].

\section{Результаты и обсужАения}

Оченка силь роста семян кукурузы сахарной после облучения в переменном магнитном поле. При облучении переменным магнитным полем, мы оценили силу роста кукурузы сахарной «Пролетарская» (элита) и провели сравнение с контрольной группой растений. Установили, что все группы семян имели высокую силу роста (80-100\% от выборки), кроме выборки, облученной 7 мТл (она имела среднюю силу роста). При сравне- нии полученных данных по облучению семян с магнитной индукцией 9, 8, 10, 4, 3 и 6 мТл выяснили, что при этой амплитуде сила роста надземной части растения от контроля достоверно была выше на 14-27\% (рис. 2).

Оценивая силу роста корневой системы, мы установили, что наибольшее стимулирующее действие оказали амплитуды 8, 1, 2, 6 и 5 мТл (рис. 3). При В = 8 мТл, сила роста экспериментальной группы растений достоверно была выше контрольной группы на 14\%.

Влияние ПеМП на онтогенез кукурузы сахарной. При облучении семян кукурузы сахарной с экспозицией в ПеМП 1 час, установили стимулирующие и угнета- 


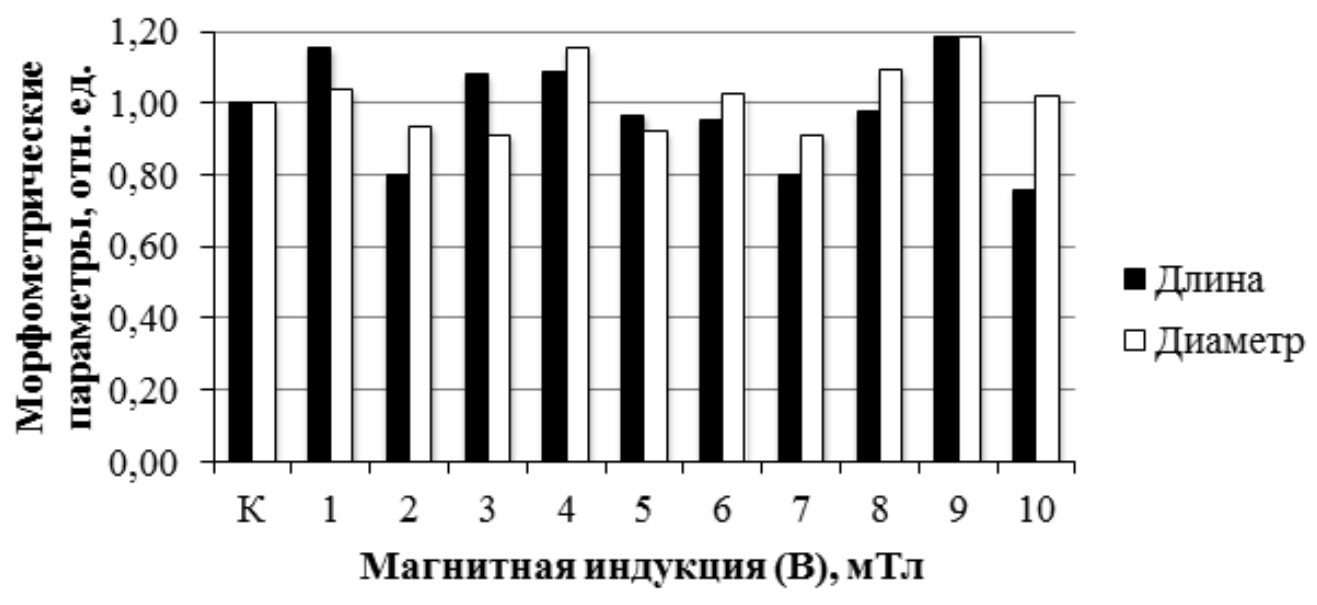

Рис. 5. Влияние ПеМП на морфометрические параметры надземной части кукурузы сахарной. Примечание: $\mathrm{K}$ — контрольная группа растений

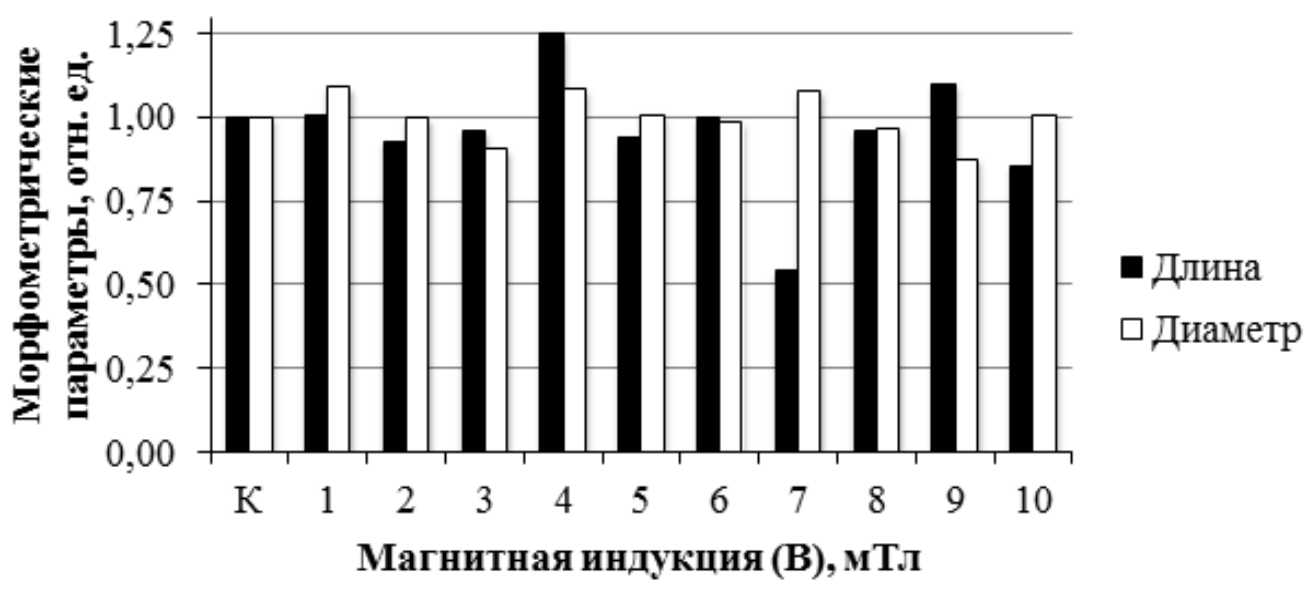

Рис. 6. Влияние ПеМП на морфометрические параметры подземной части (корневой системы) кукурузы сахарной. Примечание: $\mathrm{K}$ — контрольная группа растений

ющие рост и развитие растений амплитудные характеристики переменного магнитного поля. При магнитной индукции 3 мТл наблюдался максимальный стимулирующий эффект в 25\% при сравнении с контрольной группой растений (рис. 4). Также стимулирующий эффект в развитии семян кукурузы сахарной дали следующие амплитуды: 1 мТл (+10\% развития организма) и 10 мТл (+5\% развития организма).

Нейтральным эффектом, со статистически незначимыми отличиями, обладали амплитуды ПеМП в 4, 8 и 9 мТл.

Негативным эффектом отличались амплитуды 2, 5-7, 11-14 мТл. Наибольшее ингибирующее влияние, со зна- чением 35\% отклонения от нормального развития организма, проявили амплитуды 2, 11 и 13 мТл.

Влияние ПемП на морфометрические параметры кукурузы сахарной. По сравнению с контрольной группой, которая не подвергалась влиянию ПеМП, стимулирующим эффектом на морфометрические параметры (длина (L) и/или диаметр (D) стебля) надземной части кукурузы сахарной обладали амплитуды 9 мTл ( $\mathrm{L}=$ 19\%; $D=18 \%), 1$ мТл (L = 15\%; $D=3 \%), 4$ мТл $(L=9 \% ; D=$ 15\%), 3 мТл $(L=8 \%), 8$ мТл (D=9\%) (рис. 5).

Нейтральный эффект обнаружен при В = 5 и 6 мТл. Ингибирующее действие проявили амплитуды 2 мТл 
$(L=-20 \% ; D=-6 \%), 7$ мТл $(L=-20 \% ; D=-9 \%)$ и 10 мТл $(\mathrm{L}=-24 \%)$.

Оценивая корневую систему кукурузы сахарной при различной амплитуде облучения переменным магнитным полем, установили, что подземная часть (длина (L) и/или диаметр (D) корня) организма менее подвержена действию физического поля. Значительное ингибирующее влияние проявили 3 мТл ( $L \approx 5 \%, D=-10 \%), 7$ мТл $(\mathrm{L}=-46 \%), 10$ мТл $(\mathrm{L}=-15 \%)$. Амплитуды 2, 5, 6 и 8 мТл оказали нейтральный эффект на морфометрические параметры корневой системы (рис. 6).

Стимулирующим действием обладала амплитуда 4 мТл. При данном значении магнитной индукции длина корневой системы была на $25 \%$ более развитой, чем в контроле, а диаметр на 8\%. При В = 1 мТл длина статистически не отличалась от контроля, а диаметр был больше на 9\%. При В = 9 мТл длина была больше на 10\% относительно контроля.

\section{Выво $\triangle \mathrm{b}$}

1. При облучении семян кукурузы сахарной «Пролетарская» (элита) с экспозицией в переменном магнитном поле 1 час, установили, что при магнитной индукции 3 мТл наблюдался максимальный стимулируюший эффект в развитии семян - на 25\% при сравнении с контрольной группой растений. Также стимулирующий эффект развития кукурузы сахарной дали следующие амплитуды: 1 мТл (+10\% развития организма) и 10 мТл (+5\% развития организма). Нейтральным эффектом, со статистически незначимыми отличиями, обладали амплитуды ПеМП - 4, 8 и 9 мТл. Ингибирующим эффектом отличались амплитуды 2, 5, 6, 7, 11, 12, 13, 14 мТл. Наибольшее ингибирующее влияние, со значением 35\% отклонения от нормального развития организма, проявили амплитуды 2, 11 и 13 мТл.

2. По сравнению с контрольной группой, которая не подвергалась влиянию ПеМП, стимулирующим эффектом на морфометрические параметры (длина (L) и диаметр (D)) надземной части кукурузы сахарной обладали амплитуды 9 мТл $(\mathrm{L}=$ $19 \% ; \mathrm{D}=18 \%), 1$ мТл $(\mathrm{L}=15 \% ; \mathrm{D}=3 \%), 4$ мТл $(\mathrm{L}=$ $9 \% ; D=15 \%), 3$ мТл $(L=8 \%), 8$ мТл ( $D=9 \%)$. Нейтральный эффект обнаружен при B = 5 и 6 мТл. Ингибирующее действие проявили амплитуды 2 мТл ( $L=-20 \% ; D=-6 \%), 7$ мТл $(L=-20 \% ; D=-9 \%)$ и 10 мТл $(L=-24 \%)$. Оценивая корневую систему кукурузы сахарной, при различной амплитуде облучения переменным магнитным полем, установили, что подземная часть организма менее подвержена действию физического поля. Значительное ингибирующее влияние проявили только 3 мТл ( $L \approx-5 \%, D=-10 \%)$ и 7 мТл $(L=-46 \%)$. Амплитуды 2, 5, 6 и 8 мТл проявили нейтральный эффект на морфометрические параметры корневой системы. Стимулирующим действием обладала амплитуда 4 мТл. При данном значении магнитной индукции длина корневой системы была на 25\% более развитой, чем в контроле, а диаметр на 8\%. При В = 1 мТл длина статистически не отличалась от контроля, а диаметр был больше на 9\%. При В = 9 мТл длина была больше на $10 \%$ от контроля.

Таким образом, для экологически безопасной предпосевной обработки семян кукурузы сахарной, с целью улучшения качества посадочного материала, рекомендуется производить обработку при следующих параметрах установки: частота $f=50$ Гц, амплитуда В - преимущественно 1 мТл, 3 мТл, 4 мТл, 9 мТл.

\section{ЛИТЕРАТУРА}

1. Корниенко В.О., Кольченко О.Р., Яицкий А.С. Влияние наночастиц $\mathrm{Fe}_{3} \mathrm{O}_{4}$ на онтогенез и морфометрические показатели кукурузы сахарной (Zеа mays L.) // Современная наука: актуальные проблемы теории и практики. Серия: Естественные и технические науки. 2020. № 08/2. C. 30-36. D0I: $10.37882 / 2223-2966.2020 .08-2.09$.

2. Корниенко В.0. Влияние наночастиц $\mathrm{Fe}_{3} \mathrm{O}_{4}$ с различными типами покрытия на ранние стадии развития кукурузы сахарной (Zea mays L.) // Проблемы экологии и охраны природы техногенного региона. 2020. № 3-4. С. 88-98.

3. Еськов Е.К., Тобоев В.А. Воздействие искусственно генерируемых электромагнитных полей на биологические объекты // Вестник Чувашского университета. 2008. № 2. С. 28-36.

4. Савченко В.В., Синявский А.Ю. Изменение биопотенциала и урожайности сельскохозяйственных культур при предпосевной обработке семян в магнитном поле // Вестник ВИЭСХ. 2013. № 2 (11). С. 33-37.

5. Козырский В.В., Савченко В.В., Синявский А.Ю. Влияние магнитного поля на диффузию молекул через клеточную мембрану семян сельскохозяйственных культур // Вестник ВИЭСХ. 2014. № 2 (15). С. 16-19.

6. Козырский В.В., Савченко В.В., Синявский А.Ю. Влияние магнитного поля на транспорт ионов в клетке растений // Вестник ВИЭСХ. 2014. № 3 (16). С. 18-22.

7. К Козирський В.В., Савченко В.В., Синявський 0.Ю. Вплив магнітного поля на водопоглинання насіння // Науковий вісник НУБіП України. 2014. Вип. 194, ч. 1. С. $16-20$. 
8. Каменир Э.А. Комплексное применение электрических полей в системах подготовки семян: автореф. дис. ... д-ра тех. наук: 05.20.02. Челябинск, $1988.53 \mathrm{c}$.

9. Летова А.Н., Зейналов А.А. Использование электромагнитных излучений в технологиях возделывания сельскохозяйственных культур // Физико-технические проблемы создания новых технологий в агропромышленном комплексе: сб. науч. тр. Ставрополь: Ставропольский ГАУ, 2005. С. 366-369.

10. Попандопуло К.Х., Сидорцов И.Г. Применение магнитных полей постоянных магнитов для предпосевной обработки семян // Технологии и средства повышения надёжности машин в АПК. Зерноград: АЧГАА, 2007. С. 133-137.

11. Савченко В.В., Синявский А.Ю. Влияние предпосевной обработки в магнитном поле на посевные качества семян кукурузы // Инновации в сельском хозяйстве. 2017. № 3 (24). С. 20-24.

12. Аксенов С.И., Булычев А.А., Грунина Б.Н. и др. 0 механизмах воздействия низкочастотного магнитного поля на начальные стадии прорастания семян пшеницы // Биофизика. 1996. Т. 41, вып. 4. С. 919-924.

13. Обработка сельскохозяйственного сырья электромагнитным полем низкой частоты. Теория и практика: монография / Г.И. Касьянов, М.Г. Барышев, Р.С. Решетова и др. СПб.: Троицкий мост, 2017. 296 с.

14. ГОСТ 12038-84. Семена сельскохозяйственных культур. Методы анализа: сб. ГОСТов. М.: ИПК Издательство стандартов, 2004. 47 с.

15. Алексейчук Г.Н., Ламан Н.А. Физиологическое качество семян сельскохозяйственных культур и методы его оценки. Мн.: Право и экономика, 2005. 48 с.

() Корниенко Владимир Олегович ( kornienkovo@mail.ru),

Котюк Полина Федоровна ( daniaua411@gmail.com ), Яицкий Андрей Степанович ( yaitsky@sgspu.ru ).

Журнал «Современная наука: актуальные проблемы теории и практики»

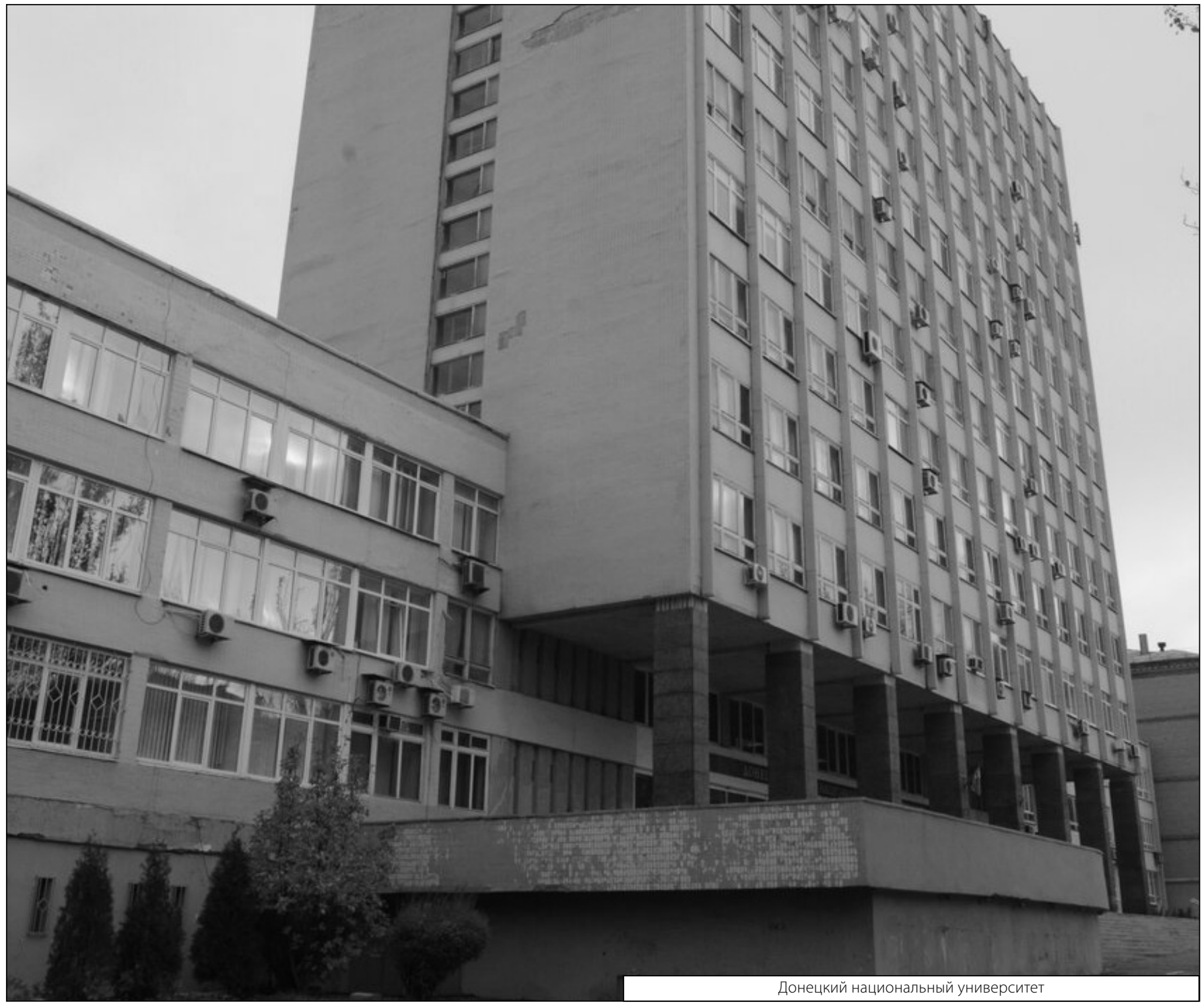

